\title{
Influence of Hail Suppression on the Hail Trend in Vojvodina, Serbia
}

\author{
Gavrilov B. Milivoj ${ }^{\mathrm{A}}$, Lazić LazarA, Milutinović Miroljub ${ }^{\mathrm{B}}$, Gavrilov M. Momčiloc \\ Received: April 2011 | Revised: May 2011 | Second Revised: May 2011 | Accepted: June 2011
}

\begin{abstract}
The influence of hail suppression by silver iodide seeding on the trend in the number of hail days [the hail trend] in Vojvodina was studied in two cases; [1] from 1967 to 2002 when there was no hail suppression and [2] from 2003 to 2010 when hail suppression existed on the whole territory.

The hail trend in Vojvodina was calculated on the basis of all observed data from all synoptic and climatological stations in the period 1967 to 2010. Previous two cases show that the hail trend was increasing when there was hail suppression. Obtained results are not in accordance with the expectation that hail suppression decreases hail in Vojvodina.
\end{abstract}

Key-words: hail, hail suppression, synoptic stations, climatological stations, mean number of days with hail, hail trend.

\section{Introduction}

In Yugoslavia, hail suppression by silver iodide seeding is carried out according to the so-called Soviet method (Sulakvelidze, 1967), which is tested by Federer et al. (1986). The same name is used in the work by Mesinger and Mesinger (I992), but here the above mentioned method is partly modified (Radinović, 1970 and Radinović, 1972) for the purpose of hail suppression by silver iodide seeding in the eastern part of Yugoslavia. One of the latest public texts with the description of hail suppression method by silver iodide seeding that is used in Vojvodina may be found in the work by Gavrilov et al. (2010). Both the original Soviet method and the modified Soviet method that is applied in Vojvodina are based on a well known seeding hypothesis: by seeding hail bearing cloud with silver iodide crystallisation nuclei, the number of potential deposition cores is increasing, since silver iodide also crystallises in a hexagonal grid like ice; thus, its small crystals will serve as additional deposition cores around which molecules of (supercooled) water vapor will collect while it is expected that ice crystals grow on additional cores as on natural cores, so that each hail grain will grow less and melt as it falls down and smaller sized hail and/or rain will fall instead of larger hail.

This hypothesis and the method based on it are applied in Vojvodina by the use of meteorological radars and rockets. Radars identify hail clouds and rockets are used for the injection and seeding of silver iodide from the ground into the clouds. Rockets reach the height of 6-8 km and each rocket contains $400 \mathrm{~g}$ of silver iodide (Vujović et al., 2007). Since 2003, hail suppression has been carried out using around 45I rocket-launching stations that are evenly distributed over the territory of Vojvodina and from three radar centers, Figure $\mathrm{I}$. Each radar center is authorized for a certain number of rocket-launching stations and by radio communication issues commands regarding when, where and how many rockets to use for firing into hail-bearing clouds. Hail suppression is operatively carried out six months a year, from i5 April to I5 October and has always been conduct-

\footnotetext{
A Chair of Physical Geography, Department of Geography, Tourism and Hotel Management, Faculty of Sciences, University of Novi Sad, Trg D. Obradovića 3, 21000 Novi Sad, Serbia

B Republic Hydrometeorological Service of Serbia, Kneza Višeslava 66, 11000 Belgrade, Serbia

c Faculty of Physics, University of Belgrade, Studentski Trg 14, 11000 Belgrade, Serbia

* Corresponding author: Milivoj Gavrilov, e-mail: gavrilov@eunet.rs
} 
ed by the Republic Hydrometeorological Service (RHMS) of Serbia, (http://www.hidmet.gov.rs/). The method of hail suppression by silver iodide seeding based on the use of rockets as described here is also applied in Serbia without the Provinces, other former Yugoslavia states, above all in Croatia, Bosnia and Herzegovina and Macedonia, other Balkan states, as well as Russia and the states formed out of USSR, China, etc. (Wieringa and Holleman, 2006).

The main goal of hail suppression is to decrease hail in order to decrease the damage caused by it, primarily in agriculture (WMO, 2007). As we know, Vojvodina is a highly agricultural area. It is important therefore to examine the impact of hail suppression on the hail in Vojvodina, after 44 years of continuous operative experience in Serbia without the provinces with hail suppression and after firing a total of approximately 400,000 rockets (Vujović et al., 2007) and spraying approximately $160,000 \mathrm{~kg}$ of silver iodide. Other influences on the hail trend, like its natural variability, weather and climate changes of all kinds (e.g. Sokolović et al., I984 and Ducić et al., 2008), were ignored in order to simplify the research.

\section{Data}

Data on hail in Vojvodina from 1967 to 2010 was analyzed in order to ascertain the influence of hail suppression on the trend in the number of hail days (hail trend). Data was assessed on the number of days with hail (e.g. Gavrilov el al., 20Io; Mesinger and Mesinger, I992; Changnon and Changnon, 2000) observed on all synoptic stations and all climatological stations (WMO, I979), Figure I. The number of operating stations whose data was used varied over the years. The largest number of operating stations was 25 in 1990 , and the minimum number was I4 in I993. The use of all meteorological stations that were operative enabled the impartial assessment of hail data. The periods before 1967 are not studied because before 1967 logical and spatial control of data were not made in RHMS. Only the number of days with hail from I5 April to I5 October, 1967 to 2010, was analyzed. The general quality and spatial coherence of observed data had been controlled before their use. From these data, the value was calculated for the mean number of days with hail per station and per a year. Finally, these values compose a time series of hail that could still be statistically processed.

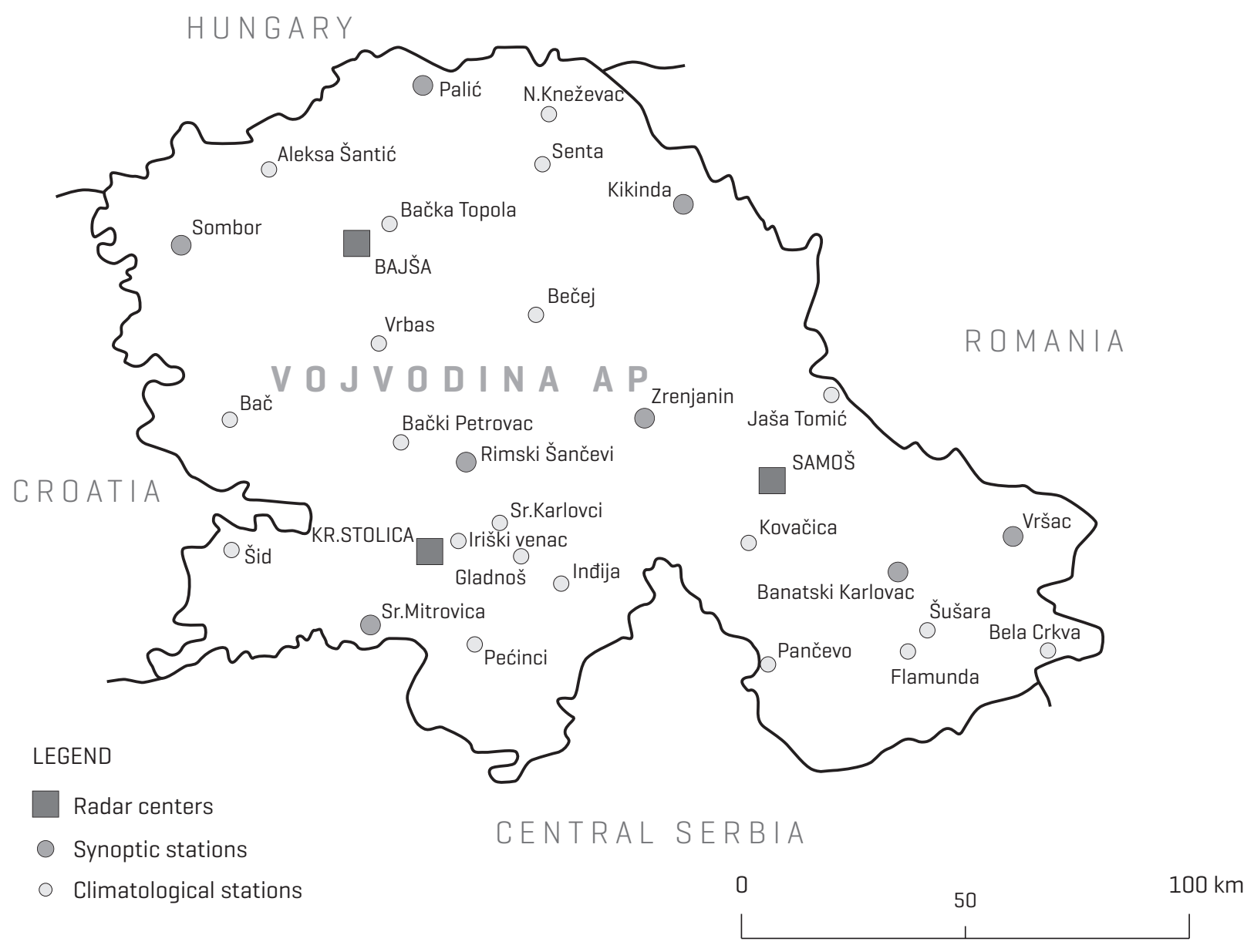

Figure 1. Positions and names of the synoptic stations, climatological stations, and radar centers in Vojvodina 
Up until now, the work by Gavrilov et al (20I0) was the only research on the efficiency of hail suppression in Serbia that used the same time series on hail as this study. The lack of other kinds of data on hail (such as the total number of hailstones, the distribution of hailstones per diameter, the maximum diameter, the total mass or hailstone kinetic energy, hailfall duration, etc. (Morgan, I988) that are usually observed in hail suppression with the help of hail pads, radars and similar stations, (e.g., Počakal et al., 2009), is a shortcoming of this research. But it could not be overcome since there are no other reliable data on hail in Vojvodina. Unfortunately, in Serbia (http:// www.hidmet.gov.rs/) different hail observations have never been undertaken and documented nor any special hail observation for the hail suppression needs and other purposes, as described in works by Federer et al. (1986) and Dessens (1998).

\section{The Method}

Generally, WMO (2007) recommends the use of statistical methods for processing of hail. In a work by Počakal and Štalec (2003) a statistical method was used to analyse hail during two periods of differing hail suppression intensity. Also, linear trend calculation is a frequently used method for the analysis of time series of atmospheric variables, such as precipitation and temperature, (e.g. Klein Tank and Können, 2003; Djordjević, 2008) and there are works where trend is used for hail analysis (e.g. Changnon and Changnon, 2000; Xie et al., 2008).

Two statistical approaches were used to process the hail trend in the same way as in the work by Gavrilov et al. (20I0). The first of them is to calculate the tendency (trend) equation of hail by fitting linear trend of mean number of days with hail per station and per year for each of the periods. Tendency equations (linear trend curve) were graphically shown together with mean number of days and with hail per year. Also, in each of the periods, the mean number of operating stations with hail was calculated.

In a second statistical approach, Mann-Kendall tests were used (Gilbert, I987) for analysing the hail trend. These tests are widely used in environmental science, because they are simple, robust and can cope with missing values and values below a detection limit. First, Kendall's tau was calculated, (Kendall, I938) for the estimation of trends in each of the time series. After that, two hypotheses were tested:

(I) null hypothesis - there is no trend in the series; and

(2) alternative hypothesis - there is a trend in the series, for a given significance level. Probability was calculated to determine the level of confidence in the hypothesis.

Since the aim of this research was to establish the influence of hail suppression on the hail trend, data processing was adapted to this requirement. Trends of hail were processed in two periods, before and after the introduction of hail suppression in Vojvodina. Here, the hail trend was compared on the same territory in two different periods with and without hail suppression which is a very good test for the assessment of the efficiency of hail suppression, (WMO, 2007).

\section{Results}

Two periods are considered in Vojvodina: 19672002, when there was no hail suppression (Gavrilov et al., 2010); and 2003-2010, when there was hail suppression on the whole territory. As noted, the time series of hail are defined in each of the two periods. By applying two statistical approaches to each of the time series, two cases are obtained

$y=-0.017 x+\mathrm{I} .275, \quad \tau=-0.27, \quad p=\mathbf{2 . 2} \% \quad(\mathrm{I})_{1,2,3}$

$y=0 . \mathrm{I} 2 \mathrm{I} x+0.397, \quad \tau=0.29, \quad p=39.9 \%(2)_{1,2,3}$

where, here and in other places in the text, the first term is the tendency linear (trend) equation, $y$ is mean number of days with hail in the territory, $x$ is time in years, $\tau$ is Kendall's tau (takes values between -I and $+\mathrm{I}$ ), $p$ is probability in percentage and significance level $\alpha=5 \%$ was the same in all cases shown.

Figures 2 and 3 show the mean number of days with hail per year (histograms) and linear trends curve of hail (straight lines) in each of the two periods, on the basis of the average of 20.6 and 15.2 stations that were operative, in order.

Figure 2 , as well as equation $(\mathrm{I})_{\mathrm{I}}$ and value $(\mathrm{I})_{2}$ show that the hail trend is negative. Testing the hypotheses will prove whether this statement is true. As the value $(\mathrm{I})_{3}$ is lower than the significance level $(\alpha=5 \%)$, one should reject the null hypothesis, and accept the alternative hypothesis. The risk to reject the null hypothesis while it is true is lower than $2.2 \%$. The statement that there is a trend is correct with probability greater than $97.8 \%$.

Figure 3 as well as equations (2) ${ }_{\mathrm{I}}$ and value (2) show that the hail trend is positive. As the value $(2)_{3}$ is greater than the significance level $(\alpha=5 \%)$, one should accept the null hypothesis. The risk to reject the null hypothesis while it is true is $39.9 \%$. 


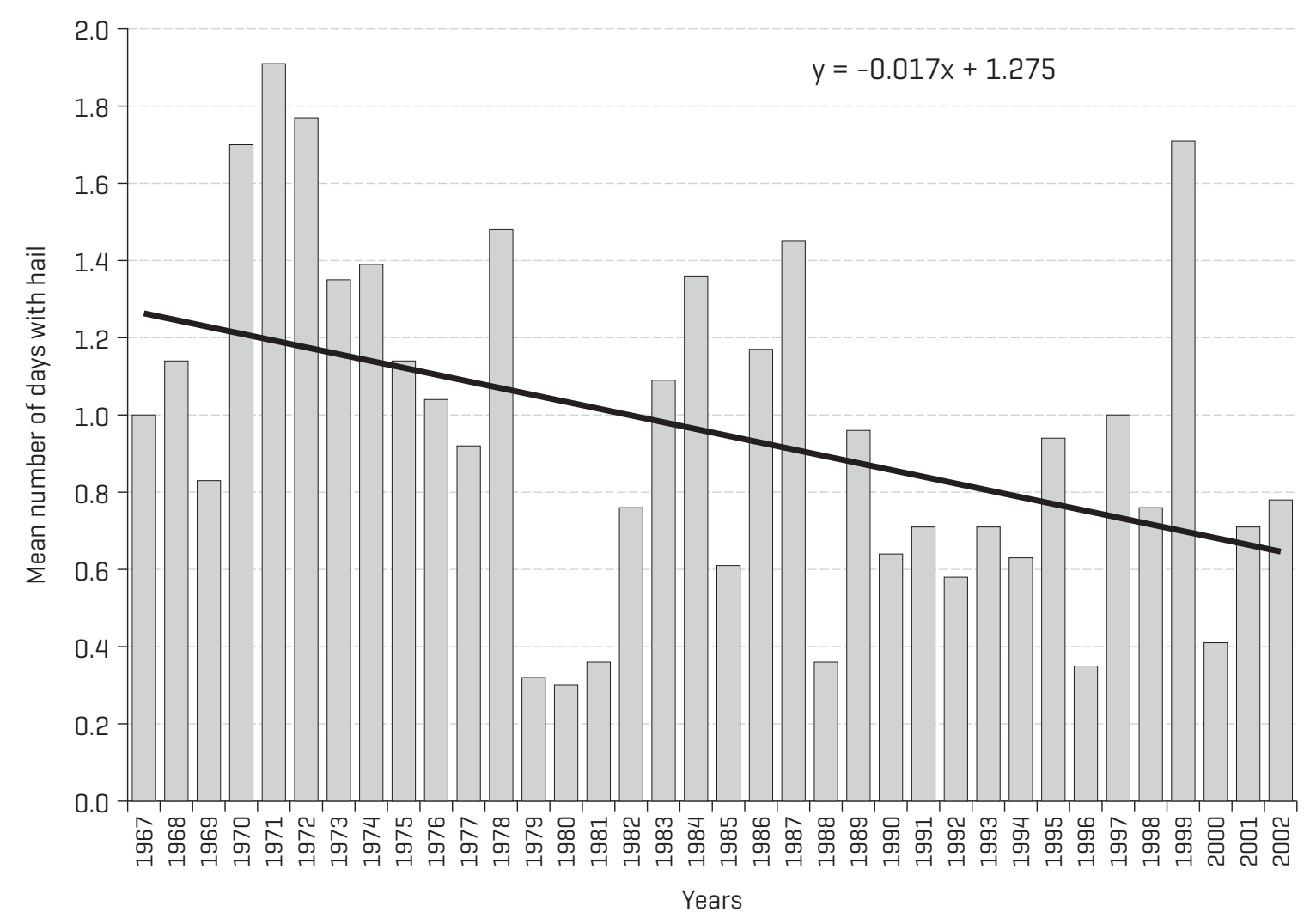

Figure 2. The mean number of days with hail per year and linear trend curve of hail from 1967 to 2002 , when there was no hail suppression in Vojvodina, [Gavrilov et al., 2010]

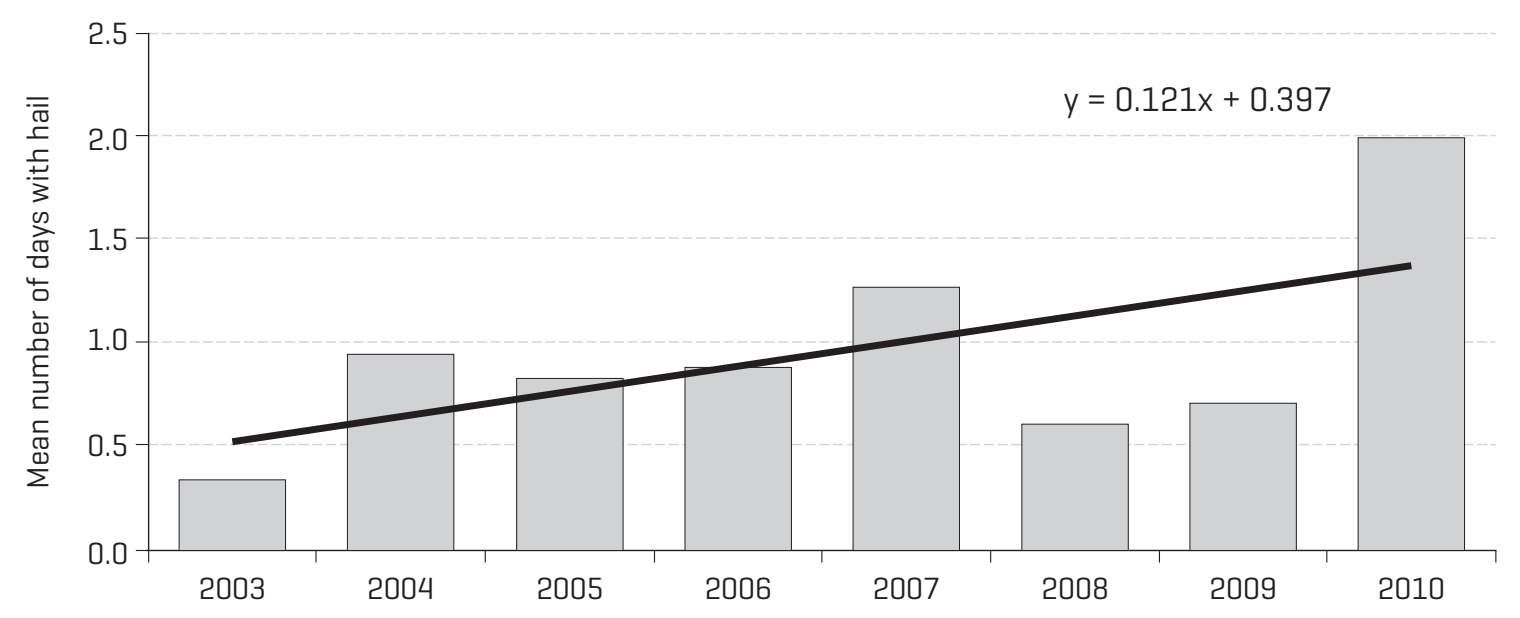

Figure 3. The mean number of days with hail per year and linear trend curve of hail from 2003 to 2010 , when there was hail suppression in Vojvodina on the whole territory

In other words, if we consider that there is a trend, it is correct with probability of $60.1 \%$.

\section{Conclusion}

The goal of this work was to study whether hail suppression program in Vojvodina carried out from 2002 to 2010 had the expected statistical influence on the hail trend, while all other influences were ignored. The hail trend was processed with two statistical approaches: a calculation of the linear hail trend equation and an application of Mann-Kendall tests. For processing, all observed data were used on the number of days with hail on all synoptic and climatological stations for the period i967-2010. Data from the previous period could not be used since they had not been controlled, and there are no other hail data in Serbia. Since the aim of this research was to ascertain the influence of hail suppression on the hail 
trend, data processing was adjusted for this condition. With reference to that, the hail trend was studied in Vojvodina in two periods.

In the first period, from I967 to 2002, when there was no hail suppression and both statistical approaches indicate that the hail trend was decreasing. In the second period, from 2003-2010, when hail suppression was carried out on the whole territory, both statistical approaches indicate that the hail trend was increasing. Hail suppression brought about an increase of the hail trend that had been decreasing in the previous period.

Previous analyses show that the hail trend increased when there was hail suppression. The obtained results are not in accordance with the expectation that hail suppression decreases hail in Vojvodina, but rather hail suppression causes an increase of hail. It seems that the question is not whether hail suppression in Vojvodina, as insufficiently scientific-based activities (Gavrilov, 2008), should be abolished, but how it should be done?

\section{Acknowledgments}

This work was supported by Project \#I76020 of the Serbian Ministry of Science and Environmental Protection. The authors are grateful for the support of $\mathrm{Mr}$. Miroljub Zarić, the efforts of Mr. Ozren Jungić. The authors sincerely appreciate the efforts of Mr. Peter Domonkos and another anonymous reviewer in improving this manuscript.

\section{References}

Klein Tank, A.M.G., Können, G.P. 2003. Trends in Indices of Daily Temperature and Precipitation Extremes in Europe, I946-99. Journal of Climate I6, 3665-3680.

Changnon, S.A., Changnon, D. 2000. Long-Term Fluctuations in Hail Incidences in the United States. Journal of Climate $\mathrm{I} 3$, 658-664.

Dessens, J. I998. A Physical Evaluation of a Hail Suppression Project with Silver lodide Ground Burnes in Southwestern France. Journal of Applied Meteorology 37, I588-I599.

Ducić, V., Savić, S., Luković, J. 2008. Contemporary Temperature Change at the Ground Surface and in the Troposphere Over Vojvodina, Serbia. Geographica Pannonica, I2, 2, 56-6I.

Djordjević, S.V. 2008. Temperature and Precipitation Trends in Belgrade and Indicators of Changing Extremes for Serbia. Geographica Pannonica I2, I, 62-68.

Federer, B., Waldvogel A., Schmid, W., Schiesser, H.H., Hampel, F., Schweingruber, M., Stahel, W., Bader, J., Mezeix, J.F., Doras, N., d’Aubignu,
G., DerMegreditchian, G., Vento, D. I986. Main Results of Grossversuch IV. Journal of Climate and Applied Meteorology 25, 917-957.

Gavrilov, M.B. 2008. Weather Modification-Hailsuppression Activity the Legal and Scientific Basis (in Serbian). "ECO-JUSTUS I" First Regional Conference on Law and Environment Protection in Economy and Practice, Kopaonik, Serbia, o9-I2 June.

Gavrilov, M.B., Lazić, L., Pešić, A., Milutinović, M., Marković, D., Stanković, A., Gavrilov, M.M. 20Io. Influence of Hail Suppression on the Hail trend in Serbia. Physical Geography 3I, 44I-454.

Gilbert, R.O. 1987. Statistical Methods for Environmental Pollution Monitoring, Van Nostrand Reinhold, New York, 336 pp.

http://www.hidmet.gov.rs/ - web site of Republic Hydrometeorological Service of Serbia.

Kendall, M. I938. A New Measure of Rank Correlation. Biometrika 30, 8I-89.

Mesinger, F., Mesinger, N. I992. Has Hail Suppression in Eastern Yugoslavia Led to a Reduction in the Frequency of Hail?. Journal of Applied Meteorology 3I, I04-III.

Morgan, M.G.Jr. I988. Observation and measurement of hailfall. Instruments and Techniques for Thunderstorm Observations and Analysis. E. Kessler, Ed., University of Oklahoma Press, II9-I35.

Počakal, D., Štalec, J. 2003. Statistical analysis of hail characteristics in the hail-protected western part of Croatia using data from hail suppression station. Atmospheric Research 67-68, 533-540.

Počakal, D., Večenaj, Ž., Štalec, J. 2009. Hail characteristics of different regions in continental part of Croatia based on influence of orography. Atmospheric Research 93, 516-525.

Radinović, Dj. I970. Protect of hail (in Serbian). Federal Hydrometeorological Institute, Belgrade, I79 pp.

Radinović, Dj. I972. Hail Control. Operative and Scientific Research Project Federal Hydrometeorological Institute, Belgrade - US Department of Commerce, Washington, I24 pp.

Sokolović, G., Radičević, D., Ranković, S. I984. Basic characteristics of the precipitation and temperature fields in Yugoslavia: Contribution to the maps of the climate atlas, Vol. I, Federal Hydrometeorological Institute, Belgrade (Yugoslavia).

Sulakvelidze, G.K. I967. Showers and hail. Gidrometeorologicheskoe Izdatelystvo (in Russian), 4I2 pp.

Vujović, D., Vučinić, Z., Babić, Z. 2007. 40 Years of Hail Suppression in Serbia, 9th WMO Scientific Conference on Weather Modification and 
Weather Modification Workshop, Antalya, Turkey, 22 -24 October 2007.

Wieringa, J., Holleman, I. 2006. If cannons cannot flight hail, what else? Meteorologische Zeitschrift. I5, 659-669.

WMO (World Meteorological Organization) (1979) Tehnical Regulations. Basic Documents No. 2.
WMO (World Meteorological Organization) (2007) Statement on the status of Weather Modification. CAS-MG2/Doc 4.4.I, Appendix C, Oslo, Norway, 24-26 September.

Xie, B., Zhang, Q., Wang, Y. 2008. Trends in hail in China during 1960-2005. Geophysical Research Letters 35,13-18. 